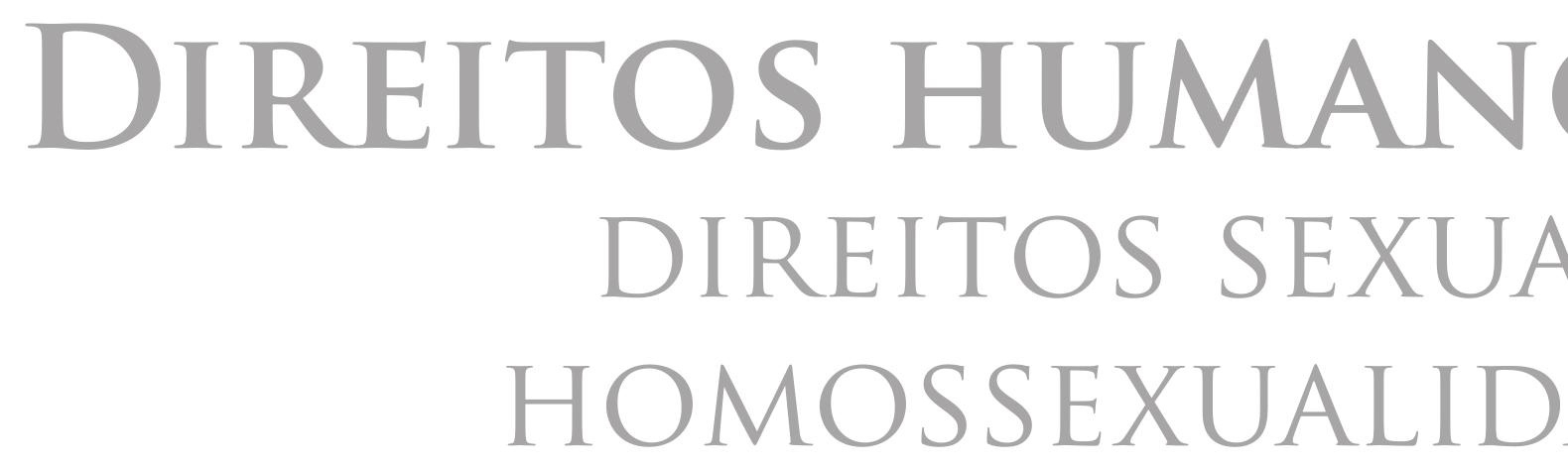




\section{DIREITOS HUMANOS, DIREITOS SEXUAIS E HOMOSSEXUALIDADE}

$$
\text { ROGER RAUPP RIOS }
$$




\title{
DIREITOS HUMANOS, DIREITOS SEXUAIS E HOMOSSEXUALIDADE
}

\section{Resumo}

Este artigo objetiva fornecer um panorama da trajetória dos Direitos Sexuais a partir da perspectiva dos Direitos Humanos. Para tanto, na primeira parte, aponta os princípios fundamentais que animam o desenvolvimento dos direitos sexuais no cenário internacional, com ênfase nos direitos de liberdade, privacidade, igualdade e respeito à dignidade da pessoa humana. Na segunda, indica as principais tendências e tensões dos direitos sexuais no Brasil.

Palavras-chave: Direitos humanos, direitos sexuais, homosexualidade, dignidade humana.

\section{HUMAN RIGHTS, SEXUAL RIGHTS AND HOMOSSEXUALITY}

\begin{abstract}
This article aims at providing an overview of the history of sexual rights from a human rights perspective. In the first part, I point out the fundamental principles that animate the development of sexual rights in the international scene, with an emphasis on freedom rights, privacy, equality, and respect to personal dignity. In the second part, I indicate the main trends and tensions of sexual rights in Brazil.
\end{abstract}

Keywords: Human rights, sexual rights, homosexuality, human dignity

\section{DERECHOS HUMANOS, DERECHOS SEXUALES Y HOMOSEXUALIDAD}

\section{Resumen}

Este artículo tiene como objetivo dar a conocer un panorama de la trayectoria de los derechos sexuales a partir de la perspectiva de los Derechos Humanos. Por tanto, la primera parte, apunta los principios fundamentales que motivan el desarrollo de los derechos sexuales en el escenario internacional, con énfasis en los derechos de libertad, privacidad. igualdad y respeto a la dignidad de la persona humana. En la segunda, indica las principales tendencias y tensiones de los derechos sexuales en Brasil.

Palabras-clave: Derechos humanos, derechos sexuales, homosexualidad, dignidad humana. 


\section{O DESENVOLVIMENTO DOS DIREITOS SEXUAIS NA PERSPECTIVA DOS DIREITOS HUMANOS}

A relação entre o Direito, entendido como ordenamento jurídico (isto é, o conjunto de instrumentos normativos estatais vigente num determinado momento, englobando atos legislativos e decisões judiciais) e a sexualidade não é novidade. Tradicionalmente, o Direito foi produzido como instrumento de reforço e de conservação dos padrões morais sexuais majoritários e dominantes. Vale dizer, o Direito atuou confirmando determinadas relações e práticas sexuais hegemônicas. Exemplos disto são, ao longo da história, a naturalização da família nuclear pequeno-burguesa, as atribuições de direitos e deveres sexuais entre os cônjuges e a criminalização de atos homossexuais.

Com a emergência de movimentos sociais reivindicando a aceitação de práticas e relações divorciadas dos modelos hegemônicos, levou-se à arena política e ao debate jurídico a idéia dos direitos sexuais, especialmente dos direitos de gays, lésbicas, travestis e transexuais. O surgimento destas demandas e o reconhecimento de alguns direitos, ainda que de modo lento e não uniforme, inaugurou uma nova modalidade na relação entre os ordenamentos jurídicos e a sexualidade. Os Direitos Sexuais devem ser compreendidos no contexto da afirmação dos Direitos Humanos, ao invés de apartá-los e concebê-los de modo paralelo aos princípios fundamentais consagrados na Declaração Universal dos Direitos Humanos de 1948.

Nesta perspectiva dos Direitos $\mathrm{Hu}-$

manos, a trajetória dos direitos sexuais tem enfrentado desafios e originalidade. De fato, conforme a história dos instrumentos internacionais demonstra os Direitos Sexuais não foram concebidos originalmente de modo autônomo aos Direitos Reprodutivos. Ao contrário, eles foram entendidos como uma espécie de complemento da idéia de Direitos Reprodutivos. Efetivamente, a preocupação principal que historicamente orientou a expressão "Direitos Reprodutivos e Sexuais" foi a denúncia da injustiça presente nas relações de gênero e a negação de autonomia reprodutiva. Não há dúvida da importância da luta contra a injustiça reprodutiva e entre os gêneros. Todavia, como a reflexão e a prática dos Direitos Sexuais deixam claro o âmbito da sexualidade vai bem além destas realidades. Esta dimensão da realidade requer levar a sério a liberdade de expressão sexual, Direito que é desafiado especialmente diante de resistência ao reconhecimento de Direitos de Homossexuais, masculinos ou femininos, transexuais e travestis. Ademais, a afirmação de Direitos Sexuais vai além da proteção desta ou daquela identidade sexual (homossexual ou travesti, por exemplo) e alcança, inclusive, práticas sexuais não necessariamente vinculadas à condição identitária, como exemplificam as práticas sadomasoquistas e a prostituição.

O que importa, portanto, é visualizar os Direitos Sexuais a partir dos princípios fundamentais que caracterizam o paradigma dos Direitos Humanos, criando as bases para uma abordagem jurídica 
que supere as tradicionais tendências repressivas que marcam historicamente as atuações de legisladores, promotores, juízes e advogados nesses domínios. A partir desta perspectiva, estabelecem-se as bases para, superando-se regulações repressivas, concretizaremse os princípios básicos da liberdade, da igualdade, da não-discriminação e do respeito à dignidade humana na esfera da sexualidade.

A luta pelo reconhecimento e a promoção dos Direitos de Homossexuais é um caso emblemático da necessidade de uma compreensão dos Direitos Sexuais na perspectiva dos Direitos Humanos. Com efeito, as trajetórias até hoje percorridas neste esforço demonstram como os mencionados princípios fundamentais são hábeis a proteger indivíduos e grupos considerados minoritários em face dos padrões sexuais dominantes. Trata-se de afirmar a pertinência da sexualidade ao âmbito de proteção dos Direitos $\mathrm{Hu}-$ manos, deles extraindo força jurídica e compreensão política para a superação de preconceito e de discriminação voltados contra todo comportamento ou identidade sexuais que desafie o heterossexismo, ora entendido como uma concepção de mundo que hierarquiza e subordina todas as manifestações da sexualidade a partir da idéia de "superioridade" e de "normalidade" da heterossexualidade.

Ao longo dos debates sobre diversidade sexual e Direitos Humanos, são invocados vários direitos: liberdade sexual; integridade sexual; segurança do corpo sexual; privacidade sexual; direito ao prazer; expressão sexual; associação sexual e informação sexual. Neste campo, os Direitos Humanos cuja invocação se revelou mais capaz de proteger homossexuais em face da homofobia e do heterossexismo foram, basicamente, o Direito de privacidade e o Direito de igualdade.

Com efeito, decisão da Corte Européia de Direitos Humanos, examinando a lei penal da Irlanda do Norte criminalizadora de práticas homossexuais consensuais entre adultos, considerou que tal tratamento viola o artigo $8^{\circ}$ da Convenção Européia de Direitos Humanos, na qual se garante o respeito à vida familiar e privada (caso Dudgeon vs. UK 1981). Desde então, predomina no Direito europeu a compreensão de que o direito humano de privacidade protege homossexuais em face de discriminação em virtude de sua orientação sexual.

Relacionado de modo indissociável à privacidade está o Direito de liberdade, mesmo porque a privacidade nada mais é do que uma manifestação, no âmbito das relações interpessoais, do próprio Direito de liberdade. Com efeito, o direito de liberdade possibilita aos indivíduos, de forma autônoma, a tomada de decisões quanto aos objetivos e aos estilos de vida. Diante da importância ímpar que a sexualidade assume na construção da subjetividade e no estabelecimento de relações pessoais e sociais, a liberdade sexual, que também se expressa como direito à livre expressão sexual, é concretização mais que necessária do direito humano à liberdade.

Não ser discriminado em virtude 
de orientação sexual é outro Direito Humano decisivo para a proteção de homossexuais em face da homofobia e do heterossexismo. Tanto na sua dimensão formal ("todos são iguais perante a lei”), quanto na sua dimensão material ("tratar igualmente os iguais e desigualmente os iguais, na medida de sua desigualdade"), o Direito de igualdade não se compadece com tratamentos prejudiciais baseados na orientação sexual. Desse modo, restrições de direitos não autorizadas em lei (por exemplo, a proibição de manifestações de carinho entre homossexuais idênticas àquelas admitidas para heterossexuais), bem como preterições de direitos fundadas em preconceito (por exemplo, justificar a exclusão de gays e lésbicas da possibilidade de adotar sob o pretexto de danos à criança), caracterizam violação do direito de igualdade, diretamente vinculada ao âmbito dos direitos sexuais.

A proibição de discriminação por orientação sexual, por vezes, é explicitamente prevista pelo Direito. Exemplos disso são as Constituições de países como a África do Sul e do Equador e de Estados brasileiros como Sergipe e Mato Grosso. Na maioria das vezes, o que ocorre é a proibição decorrente da abertura das listas de critérios proibidos de discriminação, que são expressas ao admitir, além dos fatores previstos (raça e origem, por exemplo), quaisquer outras formas de discriminação (artigo $3^{\circ}$, IV, da Constituição Federal de 1988).

Além disso, nunca é demais salientar que a discriminação por orientação sexual é uma espécie de discrimina- ção por motivo de sexo, o que é vedado textualmente pelo Direito. Isto porque a discriminação por orientação sexual é uma hipótese de diferenciação fundada no sexo da pessoa para quem alguém dirige seu envolvimento sexual, na medida em que a caracterização de uma ou outra orientação sexual resulta da combinação dos sexos dos envolvidos. Assim, Pedro sofrerá ou não discriminação por orientação sexual precisamente em virtude do sexo da pessoa para quem dirigir seu desejo ou conduta sexuais. Se orientar-se para Paulo, experimentará a discriminação; se dirigir-se para Maria, não suportará tal diferenciação. Os diferentes tratamentos têm sua razão de ser no sexo de Paulo (igual ao de Pedro) ou de Maria (oposto ao de Pedro). Contra este raciocínio, pode-se objetar que a proteção constitucional em face da discriminação sexual não alcança a orientação sexual, pois o discrímen não se define pelo sexo de Paulo ou de Maria, mas pela coincidência sexual, tanto que homens e mulheres, nesta situação, são igualmente discriminados. Este argumento não subsiste a um exame mais apurado. Isto porque é impossível a definição da orientação sexual sem a consideração do sexo dos envolvidos; ao contrário, é essencial para a caracterização da orientação sexual se levar em conta o sexo, tanto que é o sexo de Paulo ou de Maria que ensejará ou não a discriminação sofrida por Pedro. O sexo da pessoa envolvida em relação ao sexo de Pedro é que vai qualificar a orientação sexual como causa de eventual tratamento diferenciado. 
A proteção da dignidade humana é outro direito humano básico com repercussões imediatas para o exercício dos Direitos Sexuais por travestis, transexuais, gays e lésbicas. Compreendida como o reconhecimento do valor único e "irreptíval" de cada vida humana, merecedora de respeito e consideração, este direito humano requer que, na esfera da sexualidade, ninguém seja vilipendiado, injuriado ou qualificado como abjeto em virtude de orientação sexual diversa da heterossexualidade. Implica também que os projetos de vida, concernentes a tão importante dimensão da subjetividade, não sejam impostos por terceiros ao sujeito, de forma heterônoma, fazendo do indivíduo um meio para o reforço de determinadas visões de mundo, a estes externas e alheias. A violação a este princípio tão fundamental no regime jurídico dos Direitos Humanos é recorrente: basta atentar para os constrangimentos e as imposições experimentados por aqueles que não se conformam a valores, costumes e tradições, de ordem secular ou religiosa, que grupos sociais empunham e reclamam submissão.

\section{DIREITOS SEXUAIS NO BRASIL: TENDÊNCIAS E TENSÕES}

No contexto nacional, o marco mais significativo sobre diversidade sexual e Direitos Sexuais é o Programa Brasil sem Homofobia (Programa de Combate à Violência e à Discriminação contra GLTB - gays, lésbicas, transgêneros e bissexuais - e de Promoção da Cidadania de Homossexuais), lan- çado em 2004 pela Secretaria Especial de Direitos Humanos, a partir de definição do Plano Plurianual PPA 2004-2007 (Brasil 2004). Trata-se, segundo o texto do documento, de programa constituído de diferentes ações, objetivando (1) o apoio a projetos de fortalecimento de instituições públicas e não-governamentais que atuam na promoção da cidadania homossexual e/ou no combate à homofobia; (2) capacitação de profissionais e representantes do movimento homossexual que atuam na defesa de direitos humanos; (3) disseminação de informações sobre direitos, de promoção da autoestima homossexual; e (4) incentivo à denúncia de violações dos direitos humanos do segmento GLTB (Brasil 2004). Antes dele, as duas versões do Plano Nacional de Direitos Humanos (de 1996 e 2002) mencionaram o combate à discriminação por orientação sexual, sem, contudo, emprestar ao tópico maior desenvolvimento.

Como dito acima, na trajetória dos Direitos Humanos, a afirmação da sexualidade como dimensão digna de proteção é relativamente recente, tendo como ponto de partida, no contexto internacional, a consagração dos direitos reprodutivos e da saúde sexual como objetos de preocupação (Rios 2007). Em âmbito nacional, a inserção da proibição de discriminação por orientação sexual iniciou-se em virtude de demandas judiciais, a partir de meados dos anos 1990, voltadas para as políticas de seguridade social (Leivas 2003). Seguiram-se às decisões judiciais iniciativas legislativas, municipais e estaduais, 
concentradas nos primeiros anos no segundo milênio, espalhadas por diversos Estados da Federação (Vianna 2004).

Um exame do conteúdo destas iniciativas e da dinâmica com que elas são produzidas no contexto nacional chama a atenção para duas tendências: a busca por direitos sociais como reivindicação primeira onde a diversidade sexual se apresenta e a utilização do direito de família como argumentação jurídica recorrente. Estas tendências caracterizam uma dinâmica peculiar do caso brasileiro em face da experiência de outros países e sociedades ocidentais, nas quais via de regra, a luta por direitos sexuais inicia-se pela proteção da privacidade e da liberdade negativa e a caracterização jurídico-familiar das uniões de pessoas do mesmo sexo é etapa final de reconhecimento de direitos vinculados à diversidade sexual.

Além destas tendências, a inserção da diversidade sexual, assim como manifestada na legislação existente, revela a tensão entre as perspectivas universalista e particularista no que diz respeito aos direitos sexuais e à diversidade sexual, de um lado, e à luta por direitos específicos de minorias sexuais, de outro.

A primeira tendência a ser examinada é a utilização de demandas reivindicando direitos sociais como lugar onde se defendeu a diversidade sexual. Como referido, enquanto em países ocidentais de tradição democrática a luta por direitos sexuais ocorreu, inicialmente, pelo combate a restrições legais à liberdade individual, no caso brasileiro o que percebe é a afirmação da proibição da discriminação por orientação sexual como requisito para o acesso a benefícios previdenciários. Tal é o que revela, por exemplo, a superação no direito europeu da criminalização do sexo consensual privado entre homossexuais adultos - chamada sodomia - com fundamento no Direito de privacidade, ao passo que, no caso brasileiro, desde o início, o combate à discriminação foi veiculado em virtude da exclusão discriminatória contra homossexuais do regime geral da previdência social, quando se trata de pensão e auxílio-reclusão para companheiro do mesmo sexo.

Uma hipótese para a compreensão deste fenômeno vem da gênese histórica das políticas públicas no Brasil. Gestadas em suas formulações pioneiras em contextos autoritários, nos quais os indivíduos eram concebidos muito mais como objetos de regulação estatal do que sujeitos de direitos, estas dinâmicas nutrem concepções frágeis acerca da dignidade e da liberdade individuais. Alimentadas pela disputa política entre oligarquias e pelo referencial do positivismo social, as políticas públicas no Brasil caracterizaram-se pela centralidade da figura do trabalhador como cidadão tutelado, caracterizando um ambiente de progresso econômico e social autoritário, sem espaço para os princípios da dignidade, da autonomia e da liberdade individuais (Bosi 1992).

Daí a persistência de uma tradição que privilegia o acesso a prestações estatais positivas em detrimento da valorização do indivíduo e de sua esfera de liberdade e respeito à sua dignidade, dinâmica que se manifesta na história 
das demandas por Direitos Sexuais mediados pelos Direitos Sociais no Brasil.

A segunda tendência é a recorrência dos argumentos do Direito de família como fundamentação para o reconhecimento de direitos de homossexuais. De fato, não é difícil perceber que, em muitos casos, a inserção de conteúdos antidiscriminatórios relativos à orientação sexual valeu-se de argumentos de Direito de família, o que se manifesta de modo cristalino pela extensão do debate jurídico - nos tribunais e naqueles que se dedicam a estudar direitos sexuais - acerca da qualificação das uniões de pessoas do mesmo sexo. A par da polêmica sobre a figura jurídica adequada a essas uniões, é comum associar-se de modo necessário o reconhecimento da dignidade e dos direitos dos envolvidos à assimilação de sua conduta e de sua personalidade ao paradigma familiar tradicional heterossexual.

É o que sugere, por exemplo, a leitura de precedentes judiciais que deferem direitos ao argumento de que, afora a igualdade dos sexos, os partícipes da relação reproduzem em tudo a vivência dos casais heterossexuais - postura que facilmente desemboca numa lógica assimilacionista. Nesta, o reconhecimento dos direitos depende da satisfação de predicados como comportamento adequado, aprovação social, reprodução de uma ideologia familista, fidelidade conjugal como valor imprescindível e reiteração de papéis definidos de gênero. Daí, inclusive, a dificuldade de lidar como temas como prostituição, travestismo, liberdade sexual, sadomasoquismo e pornogra- fia, por exemplo. Ainda nesta linha, a formulação de expressões, ainda que bem intencionadas, como "homoafetividade", revela uma mentalidade homonormativa. Conservadora, na medida em que subordina os princípios de liberdade, igualdade e não-discriminação, centrais para o desenvolvimento dos direitos sexuais (Rios 2007) a uma lógica assimilacionista; discriminatória, porque, na prática, distingue uma condição sexual "normal", palatável e "natural" de outra assimilável e tolerável, desde que bem comportada e "higienizada". Com efeito, a sexualidade heterossexual não só é dizível como tomada por referência para nomear o indivíduo "naturalmente" detentor de direitos (o heterossexual, que não necessita ser heteroafetivo), enquanto a sexualidade do homossexual é expurgada pela "afetividade", numa espécie de efeito mata-borrão.

As razões desta recorrência ao Direito de familia podem ser buscadas na já registrada fragilidade dos princípios da autonomia individual, da dignidade humana e da privacidade que caracterizam nossa cultura. Com efeito, fora da comunidade familiar, onde o sujeito é compreendido mais como membro do que como indivíduo, mais como parte, meio e função do que como fim em si mesmo, não haveria espaço para o exercício de uma sexualidade indigna e de categoria inferior.

Uma rápida pesquisa sobre as respostas legislativas estaduais e municipais revela a predominância de duas perspectivas quanto à diversidade sexual e os direitos a ela relacionados. De um lado, diplomas legais de cunho mais 
particularista, nos quais uma categoria de cidadãos é identificada como destinatária específica da proteção: são os casos, por exemplo, da legislação paulista sobre combate à discriminação por orientação sexual, Lei No 10.948 de 2001 (São Paulo 2001); da cidade de Juiz de Fora, Lei No. 9.791 de 2000 (Minas Gerais 2000); de outro, diplomas mais universalistas, destacando-se a lei gaúcha, Lei N. ${ }^{\circ} 11.872$ de 2002 (Rio Grande do Sul 2002). De fato, enquanto os primeiros referem-se a "qualquer cidadão homossexual (masculino ou feminino), bissexual ou transgênero" (conforme o art. $1^{\circ}$ da lei mineira), o segundo, "reconhece o direito à igual dignidade da pessoa humana de todos os seus cidadãos, devendo para tanto promover sua integração e reprimir os atos atentatórios a esta dignidade, especialmente toda forma de discriminação fundada na orientação, práticas, manifestação, identidade, preferências sexuais, exercidas dentro dos limites da liberdade de cada um e sem prejuízo a terceiros" (2002, art. 19). Não se questiona, em nenhum momento, a intenção antidiscriminatória presente nestes dois modelos de respostas. Todavia, é necessário atentar para as vantagens, desvantagens e os riscos próprios de cada um.

Com efeito, a adoção de estratégias mais particularistas expõe-se a riscos importantes: reificar identidades, apontar para um reforço do gueto e incrementar reações repressivas (basta verificar o contra-discurso conversador dos "direitos especiais" e a ressurgência de legislação medicalizadora "curativa" de homossexuais). Isto sem se falar dos perigos de limitar a liberdade individual na potencialmente fluida esfera da sexualidade (preocupação expressa pela chamada 'teoria queer') e de requerer, quando acionados os mecanismos de participação política e de proteção estatal, definições identitárias mais rígidas acerca de quem é considerado sujeito da proteção jurídica específica. Neste contexto, parece preferível a adoção de estratégias mais universalistas. Elas parecem ser capazes de suplantar as dificuldades de uma concepção meramente formal de igualdade, desde que atenta às diferenças reais e às especificidades que se constroem a cada momento, sem nelas se fechar; trata-se de reconhecer a diferença sem canonizá-la, trabalhar com as identidades auto-atribuídas sem torná-las fixas e rejeitar a reificação do outro.

\section{CONCLUSÃO}

De tudo isto, conclui-se, portanto, que Direitos Sexuais, além de concretizações dos princípios mais caros ao paradigma dos Direitos Humanos (liberdade, igualdade e proteção à dignidade), são desafio presente e necessário para a consolidação da democracia, especialmente em contextos como o brasileiro, onde há fraca tradição no cultivo e na promoção destes valores.

Neste sentido, a luta contra a homofobia e o heterossexismo, que engendram a discriminação por orientação sexual sofrida por gays, lésbicas, travestis e transexuais, é arena emblemática e decisiva. Ela permite, ao mesmo tempo em que os Direitos Sexuais são desenvolvidos, superar graves injustiças e construir 
padrões mais democráticos e pluralistas no convívio social onde a diversidade e o respeito são valores básicos e necessários para todos.

\section{REFERÊNCIAS}

Bosi, A. 1992. A Dialética da Colonização. Rio de Janeiro: Companhia das Letras.

Brasil. 2004. Conselho Nacional de Combate à Discriminação. Brasil Sem Homofobia: Programa de combate à violência e à discriminação contra GLTB e promoção da cidadania homossexual. Brasília: Ministério da Saúde. Disponível em: http://bvsms.saude.gov.br/bvs/ publicacoes/brasil_sem_homofobia.pdf. Acesso em 4 de agosto de 2008.

Fraser, N. 1997. Iustitia Interrupta: Reflexion Crítica desde la Posicion "postsocialista". Bogotá: Universidad de los Andes Press.

Juiz de Fora (Município). Lei municipal $n{ }^{\circ}$ 9.791, de 12 de maio de 2000, que Dispõe sobre a ação do Município no combate às práticas discriminatórias, em seu território, por orientação sexual. Juiz de Fora, 2000. Disponível em: http:/ / www.jflegis.pjf.mg.gov.br/c_norma.php? chave $=0000023610$. Acesso em 4 de agosto de 2008.

Leivas, P. G. C. 2003. Os homossexuais diante da Justiça: relato de uma Ação Civil Pública, in A Justiça e os Direitos de Gays e Lésbicas: jurisprudência comentada. Organizado por C. Golin, F. Pocahy, R. R. Rios. Porto Alegre: Sulina.

Rio Grande do Sul (Estado). 2002. Lei n. ${ }^{\circ}$ 11.872, de 19 de dezembro de 2002 que dispõe sobre a promoção e reconbecimento da liberdade de orientação, prática, manifestação, identidade, preferência sexual e dá outras providências. Porto Alegre. Disponivel em: http://www.al.rs.gov.br/legis/. Acesso em 4 de agosto de 2008.

Rios, R. R. (org.). 2007. Em defesa dos direitos sexuais. Rio de Janeiro: Livraria do Advogado.

São Paulo (Estado). 2001. Lei estadual n. ${ }^{\circ}$ 10.948, de 5 de novembro de 2001 que dispõe sobre Dispõe sobre as penalidades a serem aplicadas à prática de discriminação em razão de orientação sexual e dá outras providências. São Paulo. Disponível em: http://www.legislacao.sp.gov. br/legislacao/index.htm. Acesso em 4 de agosto de 2008.

Vianna, A. 2004. Direitos e Políticas Sexuais no Brasil: mapeamento e diagnóstico. Rio de Janeiro: CEPESC.

Recebido em 30/06/2011.

Aprovado em 10/09/2011. 